Sex Roles, Vol. 33, Nos. 7/8, 1995

0360-0025/95/1000-0515\$07.50/0 @ 1995 Plenum Publishing Corporation

\title{
Dreams of Traditional and Nontraditional Women: Are Dream Aggression and Hostility Related to Higher Levels of Waking Well-Being? ${ }^{1}$
}

\author{
Diane Handlin ${ }^{2}$ \\ University of Medicine and Dentistry of New Jersey
}

\section{Ross Levin}

Yeshiva University

In order to determine whether varying degrees of traditionality would be manifested in specific behaviors that would be present in women's waking and dreaming life, 100 women between the ages of 22 and 79, 12\% of whom were African American, were administered a number of self-report measures of psychological well-being and were asked to complete ongoing dream diaries for a 2-week period. These instruments were then scored along with a variety of measures used to determine to what extent traditionality differentiated among the women. Randomly selected dreams from the dream diaries were scored for aggression, anxiety, emotion, hostility, self-efficacious problemsolving, and success/failure. While traditionality was not a significant factor among the self report scales, a number of significant relationships between traditionality and dream content scales were found. As predicted, nontraditionality was positively correlated with a high ratio of achievementoriented success to failure interactions, self-efficacious problem-solving, and aggressive dream interactions. However, nontraditionality was also significantly correlated with higher overall dream hostility. The results are discussed within the context of recent dream function theory as well as within a broader sociocultural context on shifting gender roles.

\footnotetext{
${ }^{1}$ This research was completed in partial fulfillment of the first author's requirements for the doctoral degree in clinical psychology at Yeshiva University. The authors wish to thank Stan Fevens, Ph.D., for his enthusiastic support and encouragment as well as his invaluable assistance. An amended version of this paper was presented at the June, 1993 meeting of the Association of the Study of Dreams, Santa Fe, NM.

${ }^{2}$ To whom requests for reprints should be addressed at 82 Park Gate Dr, Edison NJ 08820.
}

As many women have become resocialized due to decreasing family size, longer life expectancy, and higher employment, women are spending less and less time in traditional child bearing and rearing roles (Maccoby \& Jacklin, 1974; Grady, 1979, 1981; Unger, 1979; Wallston \& O'Leary, 1981; Sherif, 1982). Similarly, gender is becoming increasingly conceptualized as a sociocultural phenomenon rather than a biological fact. This shift in thinking has impacted significantly on the research on gender differences in socialization experiences for women (Hoffman, 1977; Baruch, Beiner, \& Barnett, 1987; Eagly, 1987; Stewart \& Malley, 1987) and has led to numerous studies exploring the convergence of traditional adult gender roles (e.g., Bern, 1974; Constantinople, 1973; Spence, Helmreich, \& Stapp, 1975). As the traditional feminine supportive role behaviors have become less functional, women are acquiring instrumental behaviors traditionally associated with the male gender role.

This study sought to learn more about women's personal/social identities through the exploration of dreams. Dreams, like poetry, abide paradox, invite new perspectives, and are probably the most personal products of mental operations 
available for study. Unlike waking conscious thought which can be so readily manipulated, both intentionally or otherwise, the dream lays bare the interplay of deeper motivations as well as cognitive and affective processes which remain relatively unaffected by the demand characteristics of everyday social discourse (Breger, 1967; Fromm, 1951).

While Freud (1900) emphasized the wish-fulfilling function of dreams, later theorists have viewed the dream both as a creative outlet for problem-solving and as a source for the integration of disparate affective elements that remain isolated during waking mentation (Breger, 1967; Cartwright, 1986; Erikson, 1954; French \& Fromm, 1964; Jones, 1962; Fosshage, 1983; Brown \& Donderi, 1986; Levin, 1990; Moffitt, Kramer, \& Hoffman, 1993).

Empirical research indicates that the dreams of women are in many respects similar to men, although important and persistent gender differences do exist (Hall, 1984; Urbina \& Grey, 1975), and that dream content is a sensitive and reliable barometer of the larger societal context from which it emanates (Tedlock, 1992; Urbina \& Grey, 1975). Similarly, dreams have also been used as a dependent variable to assess sociocultural changes (Kramer, Kinney, \& Scharf, 1983; Lortie-Lussier, Schwab, \& De Konnick, 1985; Trenholme, Cartwright, \& Greenberg, 1984).

Of significant import to this study, Lortie-Lussier, M., Simond, S., Rinfret, N., and De Konnick, J. (1992) found that heretofore between-gender dream content differences were not found as women took on the dual role of wage earner and homemaker. This study lends additional empirical support for the social role hypothesis (i.e., what earlier researchers thought of as gender differences may in fact be role differences (Cartwright, 1978)). Eagly (1987) contends that the distribution of social roles is responsible for behaviors and beliefs appropriate for gender roles. Rinfret, Lortie-Lussier, and De Konnick (1991) compared the manifest dream content of 18 single female college students and 19 wage-earning mothers and found that age and social role had a significant impact on dream content. Given the documented sensitivity of the dream to ongoing societal alterations, we postulate that dream content may be a useful tool in investigating differences in the degree of traditionality among women. Thus, it seems reasonable to expect that as women become less constrained by the limitations of the traditional homemaking role, dream content should reflect this. In this study, traditionality is defined as the tendency to not exercise choice in the sense of not placing a high priority on fulfilling one's internal needs in one's external life as well as to remain within more constructed and circumscribed social roles. This will be discussed in greater detail below.

Results from the gender literature on the differences between traditional and nontraditional women prove useful in developing hypotheses regarding those dream content differences which might be expected. Concerned about traditional and nontraditional labels having taken on a variety of derivative and pejorative meanings, as well as the questionable validity of many scales developed to measure this construct (i.e., ISRO; Dreyer, Woods \& James, 1981), Handlin (1991) devised a jury rating system (Levine, 1974) to classify the degree of traditionality of 60 female subjects based on a broad range of behavioral responses. Rather than defining a traditional woman only as someone invested in a familial role and a non-traditional woman as someone invested in multiple roles (Cartwright, 1983), Handlin redefined nontraditionality as the interest in and willingness to make a choice regarding internal needs and the interest in 
implementing these needs in one's external life. Internal needs can include but are not limited to roles. Consistent with this, nontraditionality was found to be significantly correlated with a woman's degree of field independence. Thus, for the purposes of this study, the construct of traditionality was based on the concept of choice. In other words, the more a woman was interested in her internal needs and motivated to implement them in her external life, the more nontraditional she was. Thus, for the purposes of this study, a more crucial determinant of a woman's degree of traditionality is whether a woman has made a choice even though she might be living what society deems to be a "traditional" or "nontraditional" role. It was expected that traditional women's dreams would reflect their tendency (whether by nature or circumstance) to not exercise choice and to remain within more constricted and circumscribed social roles.

Following Stewart and Malley's (1987) contention that it is not work per se, but the style with which work is approached that determines social roles, one would expect that varying degrees of traditionality would be manifested in specific behaviors that would be present in women's waking and dreaming life. Therefore, we hypothesized that women's dreams should contain valuable information regarding the degree to which internal representational life reflects the changing role structure of our sample and that there will be differences between the dreams of women who are classified as traditional and nontraditional. The following predictions were hypothesized:

1. traditional women will have greater levels of hostile dream content than nontraditional women.

2. traditional women will have less overall success to failure dream outcome than nontraditional women.

3. traditional women will have less aggressive dream interactions than nontraditional women.

4. traditional women will have more negative affect in their dreams than nontraditional women.

5. traditional women will have less self-efficacious dream problem solving than nontraditional women.

6. women who score neither traditional or nontraditional will have the greatest levels of dream anxiety.

\section{METHOD}

\section{Subjects}

Subjects from all across the United States included 121 women between the ages of 22 and 79 (Mean Age = 47), 12\% of whom were AfricanAmerican. They included numerous teachers and administrators solicited from a number of public and private high schools as well as women from other professions and occupations, including homemakers, and retirees. Seventy-six of the 100 women were employed either full- or part-time. The subjects were mostly middle or upper middle class women, few of whom admitted to not being heterosexual in orientation. All volunteered to participate in a study investigating the nature of contemporary women's dreams. The sample was above average in socioeconomic status with 95\% of the sample reporting joint incomes over $\$ 46,000$ and $50 \%$ of the sample reporting annual incomes over $\$ 75,000$. $70 \%$ of the women were currently married, and $30 \%$ of the sample were currently divorced, widowed or single. The sample was also above average in education (mean years of 
education $=17$ ), estimated verbal fluency (as measured by the Vocabulary subtest of the WAIS-R) $(x=110)$. Finally, most of the women (73\%) had at least one child with two children being the most frequent category.

\section{Measures}

Each subject completed six sets of research protocols. First, a demographic questionnaire and the Schedule of Recent Life Experience (Cartwright, 1983) were used to collect normative data.

\section{Measures of Psychological Well-Being}

Using degree of traditionality as the independent variable, five measures of psychological well-being were used as covariates to screen the subjects for psychological impairment or psychopathology as well as to ascertain whether there was a correlation between dream outcomes and psychological well-being: the Spielberger Trait Anxiety Inventory (STAI) (Spielberger, Lorsuch, \& Lushene, 1970); the Eysenck Personality Inventory Neuroticism Scale (EPINS) (Eysenck \& Eysenck, 1968); the Beck Depression Inventory (BDI) (Beck \& Beamesderfer, 1974); and the Personal Adjustment (PA) and Intraception (I) scales of the Adjective Checklist (Gough \& Heilbrun, 1965).

\section{Measures of Traditionality}

Four scales were used by the jury to determine the subject's degree of traditionality: 1) an Attitudes Questionnaire developed by the investigator to assess attitudes toward work, leisure, interpersonal, and spiritual spheres; 2) a Role Inventory (Cartwright, 1983) in which subjects were asked to rank order their most preferred and least preferred roles; 3) a John and Mary type verbal led projective story (based on Horner, 1972); 4) a 4-point self-rating scale developed by the first author (subjects were asked to circle whether they were traditional, somewhat traditional, somewhat nontraditional, nontraditional). In addition, the TraditionalLiberated Social Stereotype Scale of the Adjective Checklist (TLSS) and the Traditional-Liberated Self-concept Scale (TLSC) (Cartwright, 1983) were administered to cross-validate the jury rating of traditionality.

\section{Other Waking Measures}

The Vocabulary subtest of the WAIS-R (Wechsler, 1981), the MarloweCrowne Social Desirability Scale (Marlowe \& Crowne, 1964) and the Lie scale of the Eysenck Personality Inventory (Eysenck \& Eysenck, 1968) were also administered to control for the possible confounding effects of verbal fluency, social desirability, and conscious deception respectively.

\section{Waking and Well-Being Measures Results}

As all subjects were well within population norms on the five waking measures of psychological well-being, additional one-way analyses of variance were conducted for only those subjects $(n=67)$ who scored 1,2 (nontraditional), 4 (midtraditional), 6, 7 (traditional) on the traditionality measures to determine whether there were between-group differences on any of these measures. Dreams from the subjects who were dropped out of the ANOVAS 
performed on extreme groups were reserved for use in the regression analysis and later qualitative analysis. As seen in Table I, the traditional women reported the least waking life events stress, but scored highest on both the Lie and Social Desirability scales. Nontraditional women had the least waking depression and the highest WAIS-R Vocabulary scores. Women in the middle reported greater levels of waking anxiety than either the traditional or nontraditional groups. Post-hoc hierarchical multiple regressions and ANOVAS found that social desirability was not a significant moderator in the relationship between jury ratings and dream content variables.

Table I. Traditionally, Waking, and Personality Variables ANOVA Results

\begin{tabular}{|c|c|c|c|c|c|c|}
\hline \multirow{3}{*}{$\frac{\text { Variable }}{\text { Anxiety (STAI) }}$} & \multicolumn{4}{|c|}{ Means and SD } & \multirow[b]{2}{*}{$f$ Value } & \multirow[b]{2}{*}{$p$ Value } \\
\hline & \multicolumn{2}{|c|}{ Nontrad. } & \multicolumn{2}{|c|}{ Middle Trad. } & & \\
\hline & $M$ & 35.1 & 43.9 & 35.1 & $F(2,64)=7.00$ & $.002^{\mathrm{b}}$ \\
\hline & SD & 8.4 & 8.0 & 8.1 & & \\
\hline \multirow[t]{2}{*}{ Depression (BDI) } & $M$ & 3.8 & 8.0 & 7.3 & $F(2,64)=3.50$ & $.04^{\mathrm{a}}$ \\
\hline & SD & 3.0 & 6.3 & 6.2 & & \\
\hline \multirow[t]{2}{*}{ Lying (EPI) } & $M$ & 2.1 & 1.9 & 2.9 & $F(2,64)=4.50$ & $.02^{\mathrm{a}}$ \\
\hline & SD & 1.2 & 1.0 & 1.4 & & \\
\hline \multirow[t]{2}{*}{ Ncuroticism (EPI) } & $M$ & 8.7 & 11.4 & 10.9 & $F(2,64)=1.60$ & .21 \\
\hline & SD & 5.3 & 4.2 & 5.6 & & \\
\hline \multirow[t]{2}{*}{ Intraccption (ACL) } & $M$ & 16.1 & 13.3 & 14.9 & $F(2,64)=1.60$ & .22 \\
\hline & SD & 5.0 & 5.1 & 4.4 & & \\
\hline \multirow[t]{2}{*}{ Social Desirability (MC) } & $M$ & 10.8 & 10.0 & 15.8 & $F(2,64)=11.00$ & $.000^{\mathrm{C}}$ \\
\hline & SD & 4.6 & 4.5 & 5.0 & & \\
\hline \multirow[t]{2}{*}{ Persona] Adjustment (ACL) } & $M$ & 11.1 & 8.0 & 9.9 & $F(2,64)=2.50$ & .09 \\
\hline & SD & 3.9 & 4.3 & 4.2 & & \\
\hline \multirow[t]{2}{*}{ Stress (SRE) } & $M$ & 291.7 & 203.4 & 167.0 & $F(2,64)=3.30$ & $.04^{\mathrm{a}}$ \\
\hline & SD & 198.7 & 131.0 & 169.1 & & \\
\hline \multirow[t]{2}{*}{ Vocabulary IQ (WAIS) } & $M$ & 112.4 & 111.3 & 104.5 & $F(2,64)=3.80$ & $.03^{\mathrm{a}}$ \\
\hline & SD & 11.4 & 10.2 & 11.3 & & \\
\hline
\end{tabular}

\section{Measures of Traditionality Results}

As seen in Table II, the TLSS and TLSC gender role measures correlated significantly with each other and with the jury assessment of traditionality. Interestingly, subjects' self-rating did not correlate with either the TLSS or the TLSC but did demonstrate a high degree of concordance with the jury determination. Post-hoc hierarchical multiple regressions and ANOVAS found that age and employment were not significant moderators in the relationship between jury ratings and dream content variables.

The Jury. In order to maximize the level of accuracy of group membership assignment and to avoid the potential bias effects of self-selection, a jury of three women was carefully selected by the first author and trained to review the four measures of traditionality. Jury inter-rater reliability was found to be .83 . 
Table II. Correlations for Jury Rating and Traditionality Measures

\begin{tabular}{cccccc}
\hline Variable & Age & Jury Rating & TLSC & TLSS & Self Rating \\
\hline Jury Rating & $.34^{\mathrm{b}}$ & - & & & \\
TLSC & -.19 & $.24^{\mathrm{a}}$ & - & & \\
TLSS & .09 & $.43^{\mathrm{b}}$ & $.54^{\mathrm{b}}$ & & - \\
Self Rating & $.38^{\mathrm{b}}$ & $.67^{\mathrm{b}}$ & -.05 & .09 & \\
\hline
\end{tabular}

$\mathrm{a}<<.05$.

${ }_{\mathrm{b}}^{\mathrm{p}}<.01$.

In making a decision about a woman's degree of traditionality, an attempt was made to ascertain whether a woman placed a high priority on fulfilling her internal needs. In middle class society today there is a wide spectrum of opportunities available for women. Thus, it might be expected that women will have various options open to them. The more able to identify her internal needs, and the more determination a woman showed in giving priority to her own needs, the more nontraditional she tended to be rated. In many instances, however, the traditional woman was, in fact, someone for whom family responsibilities took precedence over professional and career aspirations, while the nontraditional woman was someone for whom family was only one of many role investments. This is consistent with Cartwright's (1983) definition of a traditional woman as one who is invested in her role as wife, whereas a nontraditional woman is invested in a number of roles.

In this study, using the relational model of Jean Baker Miller (1984), the jury also determined that nontraditional women would be able to display "self-empathy," in the sense of believing it to be important to care for their own interests and needs, as well as others'. This was different from most research on these constructs which labels working women nontraditional and homemakers traditional. The jury in the present study qualified this, finding that, today, a more crucial determination of a woman's degree of traditionality is whether a woman is able to make a choice even though she might be living what society deems to be a "traditional" or "nontraditional" role. Based on this, subjects were rated on a 7-point scale. For the present study, 30 subjects received a 6 or 7 (traditional), 21 subjects received a 1 or 2 (nontraditional), and 16 subjects received a middle score of 4 (moderate). 15 subjects received a 5 (somewhat traditional) and 17 subjects received a 2 (somewhat nontraditional).

The results of the TLSS and TLSC were also used by the Jury.

\section{Dream Collection}

Each subject was given a dream booklet and asked to record her dreams for a two-week period. This time duration was chosen to prevent dream collection solely from the time when a subject might be experiencing her menstrual cycle.

\section{Dream Content Measures}

The following dream content scales from the Hall and Van de Castle (1966) and Gottschalk and Gleser (1969) systems were used: Anxiety and Hostility (Gottschalk \& Gleser, 1969); Emotions, Achievement, Outcome, 
Environmental Press, and Friendly and Aggressive Social Interactions (Hall \& Van De Castle, 1966). In addition, Breger, Hunter, and Lane's (1971) Thematic Dimension Outcome Scale was utilized.

\section{Dream Selection}

Three dreams with a minimum of 70 words (range $=70$-354) were randomly selected from each subject's pool of dreams for scoring. Varying dream length was treated by averaging the number of words across each subject's three dreams to obtain the subject's average dream word length. Then, the final weighted dream score was obtained by adding the scores of the two coders on each of the variables, dividing by two and then multiplying by the average dream word length.

\section{Dream Coding and Reliability}

Each dream was scored by two coders who had a background in psychology. Hall and Van de Castle's (1966) percentage-of-perfect-agreement was used to assess reliability. The reliabilities achieved in this study are comparable to those reported by Hall and Van de Castle (1966) and range from .52 (efficacy-other) to .96 (outcome) with most falling above 80 .

\section{Procedure}

Subjects were contacted by the first author and made aware of the conditions of participation and were assured of their confidentiality. Subjects were given the self-report questionnaires and told that they would need to keep a record of their dreams for a consecutive two-week period. 50 of the subjects were seen in groups. Those unable to attend were given the protocols individually. At the end of five months, 118 of 121 subjects returned the completed questionnaires and dream protocols. 100 of these had recorded at least three dreams of 70 words or more, the criterion often cited for the validity of scoring dreams for content (Hall \& Van de Castle, 1966).

\section{Data Analysis}

All six hypotheses were tested with all subjects using simple regression analysis procedures in SPSS-X. In the regression analysis, the predictor was jury rating degree of traditionality as a continuous variable. The criteria were the following dream variables: 1) overall hostile dream content; 2) achievementoriented success/failure; 3) friendly/aggressive social interactions; 4) negative emotion; 5) self-efficacy in problem solving; and 6) anxiety.

A single additional between groups ANOVA analysis was then done in order to test the sixth hypothesis, that women moderate in the traditionality variable will have significantly more anxious dream content compared to both the very traditional and very non-traditional women. In order to define distinct groups for one-way ANOVA analysis, the 3's and 5's were eliminated from this particular statistical analysis.

\section{RESULTS}

\section{Hypothesis 1: Hostility}

A linear regression analysis found a significant relationship between 
traditionality and hostile dream content. As seen in Table III, degree of traditionality (defined by Jury rating) was significantly correlated with less Hostility Inward $(p<.05)$, less Hostility Ambivalent $(\mathrm{p}<.001)$, and less Hostility All $(p<.001)$ such that the more traditional the woman, the less hostility revealed in her dreams.

Table III. Nontraditional Jury Rating and Dream Variables

\begin{tabular}{|c|c|c|c|}
\hline \multicolumn{4}{|c|}{ Regression Analysis Results } \\
\hline Variable & $p$ Value & $r$ & $r^{2}$ \\
\hline Aggression & .02 & $-.24^{\mathrm{b}}$ & .056 \\
\hline Anxiety & .03 & $-.22^{b}$ & .048 \\
\hline \multicolumn{4}{|l|}{ Efficacy } \\
\hline Self & .06 & -.190 & .036 \\
\hline Other & .01 & $-.25^{\mathrm{b}}$ & .063 \\
\hline \multicolumn{4}{|l|}{ Emotion } \\
\hline Negative & .01 & $-.25^{\mathrm{b}}$ & .060 \\
\hline \multicolumn{4}{|l|}{ Hostility } \\
\hline Ambivalent & .001 & $-.31^{\mathrm{c}}$ & .085. \\
\hline Inward & .05 & $-.10^{\mathrm{b}}$ & .039 \\
\hline Total $^{\mathrm{a}}$ & .001 & $-.31^{c}$ & .097 \\
\hline Outcome & .05 & $-.10^{b}$ & .040 \\
\hline Success & .09 & -.17 & .029 \\
\hline Success/failure & .04 & $-.21^{\mathrm{b}}$ & .042 \\
\hline
\end{tabular}

\section{Hypothesis 2: Achievement Oriented Success/Failure}

A significant relationship between traditionality and achievement oriented success/failure dream content was also found. Degree of traditionality was significantly correlated with achievement oriented success/failure dream content such that the more nontraditional the woman, the more success/failure revealed in her dreams.

\section{Hypothesis 3: Aggression}

A linear regression analysis found a significant relationship between traditionality and aggressive dream content with degree of traditionality significantly correlated with less aggressive dream content. Thus, the more nontraditional the woman, the more dream aggression.

\section{Hypothesis 4: Negative Affect}

A significant relationship was also found between traditionality and negative dream content with degree of traditionality significantly correlated with less negative emotion dream content. Again, the more nontraditional the woman, the more negative emotion dream content.

\section{Hypothesis 5: Self-Efficacious Problem-Solving/Empowerment}


Dream scales used in the analysis of this hypothesis are thematic role selfefficacy, thematic role other efficacy and outcome dream content.

\section{Thematic Role Self-Efficacy}

A linear regression analysis indicated a trend approaching significance with thematic role self-efficacy dream content. Again, the more nontraditional the woman, the more self-efficacy dream content revealed in her dreams.

\section{Thematic Role Other Efficacy}

A linear regression analysis found a significant relationship between traditionality and thematic role other efficacy dream content. Degree of traditionality was correlated significantly with thematic role other efficacy dream content. Again, the more nontraditional the woman, the more other efficacy dream content revealed in her dreams.

\section{Outcome Dream Content}

A linear regression analysis found a significant relationship between traditionality and outcome dream content. Degree of traditionality was correlated significantly with outcome dream content. Again, the more nontraditional the woman, the more desirable dream outcome revealed in her dreams.

\section{Hypothesis 6: Anxiety}

A linear regression analysis found a significant relationship between anxiety dream content and degree of traditionality. The more traditional the woman, the lower the dream anxiety.

A one-way ANOVA found no significant differences in anxiety dream content of the three groups of women $[\mathrm{F}(2,64)=2.70, p<.07]$. However, even though it was not significant, women in the middle and nontraditional women had more anxiety in their dream content than the traditional women. Women in the middle tended to demonstrate the highest levels of dream anxiety $[\mathrm{F}(2,64)=2.70, p<.07]$.

\section{DISCUSSION}

The results of the present study suggest that the dreams of women can be differentiated as a function of degree of traditionality. A number of significant relationships between traditionality and dream content scales were found, although not all in the predicted direction. Specifically, nontraditionality was positively correlated with a higher ratio of achievementoriented success to failure, self-efficacious problem-solving, and aggressive dream interactions. Contrary to prediction, however, nontraditionality was also significantly related to higher overall dream hostility. With regards to dream anxiety, women who scored in the middle on the traditionality continuum tended to demonstrate the highest levels, providing partial confirmation for this hypothesis.

The data is consistent with results from earlier studies that used dreams as a dependent variable to assess sociocultural changes (Kramer, Kinney, \& Scharf, 1983; Lortie-Lussier, Schwab, \& De Konnick, 1985; Trenholme, Cartwright, \& 
Greenberg, 1984). Unlike these studies, however, the present investigation demonstrates a relationship between recalled dream content and degree of traditionality without a major emotional stressor being present.

On the whole, an interesting pattern emerges wherein the traditional women appear to be less distressed than the other groups of women on most dream measures such as hostility, aggression, negative emotion, and positive dream outcome. There are several possible explanations for these findings. First, traditionality may serve as a buffer against the outbreak of psychological distress and negative affect as revealed in the dream content measures. That is, the traditional women, who have not evidenced a particular concern with "choice" of role, find themselves in a more conventionally prescribed and perhaps, more comfortable role and as a result, are experiencing an absence of conflict.

A second explanation of this study's results and one most consistent with the bulk of empirical dream research (e.g., Levin, 1990) may be that the dreams of the nontraditional women reflect more adaptive dream work. It should be noted that although the nontraditional women have the highest hostility, aggression, and anxiety in their dreams, they have the least depression in their waking life. At the very least, this raises a question concerning the desirability of having some anxiety and other intense emotions in one's dreams. Perhaps there is an optimal level of anxiety that contributes more to a woman's psychological well-being than does comfort with one's prescribed role. Along these lines, Breger (1969) has speculated that human beings have two main information processing systems. One is primarily action oriented and involved with information necessary for instrumental behaviors. The other is a less action-oriented information processing system that gradually develops and maintains a person's sense of self and is more associated with sleep and dreams. Consistent with many theorists, (Cartwright, 1986; Fosshage, 1983; Fiss, 1986) Breger believes significant consolidation of the self takes place during this time.

The presence of dream anxiety coupled with an absence of waking life depression which characterized the nontraditional women in this study finds some support from studies of laboratory collected dreams. Cartwright et al. (1984) found an absence of depression in the waking state of nondepressed divorcing women to be correlated with dream anxiety. Similarly, Melstrom and Cartwright (1983) found increases in dream anxiety from first dream report to last dream report of the same night to be characteristic of successful psychotherapy patients. However, one must keep in mind the caution that the remembered dream which is the basis of this study is a highly selected one of all dreams and so differs from the laboratory collected dreams that were used in the above cited studies.

Perhaps the nontraditional women in the present study who are making unconventional choices are consolidating a new sense of self. As a result, their dreams may reflect this difficult psychological work in the form of increased hostility, aggression, and anxiety. In this regard, the jury's finding that on the subjective paper and pencil measures, women in the mid-range of degree of traditionality seem to be least satisfied with their lives and most confused about their role is most interesting. Similarly, the finding by the jury that women who described the most marked conflict, frustration, or unsatisfying self-sacrifice in the subjective paper and pencil measures such as the John and Mary type projective story tended to be more traditional is consistent with these formulations. 


\section{REFERENCES}

Baruch, G. K., Beiner, L., \& Barnett, R. C. (1987). Women and gender in research on work and family stress. American Psychologist, 42, 130-136.

Beck, A., \& Steer, R. (1987). Beck Depression Inventory manual. New York: Harcourt Brace Jovanovich.

Belenky, M., Clinchy, B., Goldberger, N., \& Tarule, J. Women's ways of knowing. New York: Basic Books, 1986.

Bem, S. L. (1974). The measurement of psychological androgyny. Journal of Consulting and Clinical Psychology, 42, 155-162.

Breger, L. (1967). The function of dreams. Journal of Abnormal Psychology Monograph, 72, 1-28.

Breger, L. (1969). Dream function: An information processing model. In L. Breger (Ed.), Clinical-cognitive psychology. Englewood, NJ: Prentice-Hall.

Brown, R. J., \& Donderi, D. C. (1986). Dream content and self-reported wellbeing among recurrent dreamers, past-recurrent dreamers, and nonrecurrent dreams. Journal of Personality and Social Psychology, 50, 612-623.

Cartwright, R. D. (1978). A primer on sleep and dreaming. Reading, MA: AddisonWesley.

Cartwright, R. D. (1986). Affect and dream work from an information processing point of view. The Journal of Mind and Behavior, 7, 411-428.

Cartwright, R. D., Lloyd, S., Nelson, J. B., \& Bass, S. (1983). The traditional-liberated women dimension: Social stereotype and self-concept. Journal of Personality and Social Psychology, 44, 581-588.

Cartwright, R., Lloyd, S., Knight, S., \& Trenholme, I. (1984). Broken dreams: A study of the effects of divorce and depression on dream content. Psychiatry, 47, 251-259.

Constantinople, A. (1973). Masculinity-femininity: An exception to the famous dictum. Psychological Bulletin, 80, 389-407.

Dreyer, N., Woods, N., \& James, S. (1981). 1SRO: A scale to measure sex-role orientation. Sex Roles, 7, 173-182.

Eagly, A. (1987). Sex differences in social behavior: A social role interpretation. Hillsdale, NJ: Erlbaum.

Erikson, E. H. (1954). The dream specimen of psychoanalysis. Journal of the American Psychoanalytic Association, 2, 5-56.

Eysenck, H., \& Eysenck, S. (1968). Manual for the Eysenck Personality Inventory. San Diego, CA: Educational and Industrial Testing Service.

Fiss, H. (1986). An empirical foundation for a self psychology of dreaming. Journal of Mind and Behavior, 7, 161-192.

Fosshagc, J. L. (1983). The psychological function of dreams: A revised psychoanalytic perspective. Psychoanalytic Contemporary Thought, 6, 641667.

French, T., \& Fromm, E. (1964). Dream interpretation. New York: Basic Books.

Freud, S. (1953). The interpretation of dreams. Standard Edition (vol. 4 and 5). London: Hogarth Press.

Freud, S. (1953). New introductory lectures on psychoanalysis. Standard Edition (vol. 22). London: Hogarth Press.

Fromm, E. (1951). The forgotten language. New York: Rinehart.

Gilligan, C. (1982). In a different voice: Psychological theory and women's development. Cambridge, MA: Harvard University Press.

Gough, H., \& Heilbrun, A. (1983). The Adjective Checklist Manual. CA: Consulting Psychologists.

Gottschalk, L. A., Winget, C. N., \& Gleser, G. C. (1969). Manual of instructions for using the Gottschalk-Gleser Content Analysis scales: Anxiety, hostility, and social alienation-personal disorganization. Berkeley and Los Angeles: University of California Press.

Hall, C. S., Domhoff, G. W., Blick, K. A., \& Weesner, K. E. (1982). The dreams of college men and women in 1950 and 1980: A comparison of dream content and sex differences. Sleep, 5, 188-194. 
Hall, C. S., \& Van de Castle, R. (1986). The content analysis of dreams. New York: Appleton-Century-Crofts.

Handlin, D. (1991). Degree of traditionality as it affects women's field dependence-independence. Unpublished predoctoral dissertation, Yeshiva University.

Helson, R., \& Picano, J. (1990). Is the traditional role bad for women? Journal of Personality and Social Psychology, 59, 311-320.

Hoffman, L. (1977). Changes in family roles, socialization, and sex differences. American Psychologist, 32, 644-657.

Horner, M. (1972). Toward an understanding of achievement-related conflicts in women. Journal of Social Issues, 28, 157-174.

Jones, R. M. (1962). Ego synthesis in dreams. Cambridge, MA: Schenkman.

Josselson, R. (1987). Finding herself: Pathways to identity development in women. San Francisco: Jossey-Bass.

Kramer, M., Kinney, L, \& Scharf, M. (1983). Sex differences in dreams. Psychiatric Journal of the University of Ottowa, 8, 1-4.

Levin, R. (1990). Psychoanalytic theories on the function of dreaming: A review of the empirical dream research. In J. Masling (Ed.), Empirical studies of psychoanalytic theories (Vol 3). Hillsdale, NJ: Analytic Press.

Levine, M. (1974). Scientific method and the adversary model. American Psychologist, 29, 661-667.

Lortie-Lussier, M., Schwab, C, \& De Konnick, J. (1985). Working mothers versus homemakers: Do dreams reflect the changing roles of women? Sex Roles, 12, 1009-1021.

Lortie-Lussier, M., Simond, S., Rinfret, N., \& De Konnick, J. (1992). Beyond sex differences: Family roles' impact on women's and men's dreams. Sex Roles, 267, 79-95.

Maccoby, E. E., \& Jacklin, C. N. (1974). The psychology of sex differences. Stanford, CA: Stanford University Press.

Marlowe, D., \& Crowne, D. P. (1964). The approval motive: Studies in evaluative dependence. New York: Wiley.

Melstrom, M. A., \& Cartwright, R. D. (1983). Effects of successful vs. unsuccessful psychotherapy outcome on some dream dimensions. Psychiatry, 46, 51-65.

Miller, J. B. (1984). The development of women's sense of self. Work in Progress: Stone Center for Developmental Services and Studies. Wellesley, MA: Wellesley College.

Moffitt, A., Kramer, M., \& Hoffmann, R. (Eds.) (1993). The functions of dreaming. Albany: SUNY Press.

Rinfret, N., Lortie-Lussier, M., \& De Konnick, J. (1992). The dreams of professional mothers and female students: An exploration of social roles and age impact. Dreaming, 1, 179-191.

Sherif, C. W. (1982). Needed concepts in the study of gender identity. Psychology of Women Quarterly, 6, 375-398.

Spence, J. T., Helmreich, R., \& Stapp, J. (1975). Ratings of self and peers on sex role attributes and their relation to self-esteem and conceptions of masculinity and femininity. Journal of Personality and Social Psychology, 32, 29-39.

Spielberger, C, Gorsuch, R., \& Lushene, R. (1970). Manual for the state-trait anxiety inventory. Palo Alto: Consulting Psychologists Press.

Stewart, A. J., \& Malloy, J. E. (1987). Role combination in women: Mitigating agency and communion. In F. Crosby (Ed.), Spouse, parent, worker: On gender and multiple roles. New Haven, CT: Yale University Press.

Tedlock, B. (Ed.). (1992). Dreaming: Anthropological and psychological interpretations. Santa Fe, NM: SAR Press.

Trenholme, I., Cartwright, R., \& Greenberg, G. (1984). Dream dimensions during a life change. Psychiatry Research, 12, 35-45.

Unger, R. K. (1979). Female and male: Psychological perspectives. New York: Harper \& Row. 
Urbina, S., \& Grey, A. (1975). Cultural and sex differences in the sex distribution of dream characters. Journal of Cross Cultural Psychology, 3, 358-364.

Wallston, B. S., \& O'Leary, V. E. (1981). Sex and gender make a difference: The differential perceptions of women and men. Review of Personality and Social Psychology, 2, 9-41.

Wechsler, D. (1981) WAIS-R manual. San Antonio. TX: Harcourt, Brace, Jovanovich. 